$p$-ISSN 1693-9484, $e$-ISSN : 2621-8313

Majalah Ilmiah Bahari Jogja (MIBJ)

Vol. 17 No. 1, Februari 2019 (37-50)

DOI : $10.33489 /$ mibj.v17i1.198

(C) 2019 Akademi Maritim Yogyakarta

BAHARI JOGA

\title{
Evaluasi Kualitas Website Pemerintah Desa Sidoluhur Godean Berdasarkan Persepsi Pengguna
}

\author{
Fajar Nugroho $^{1 *}$, Bambang Soedijono ${ }^{2}$, Armadyah Amborowati $^{3}$ \\ ${ }^{1,2,3}$ Magister Teknik Informatika, Universitas Amikom Yogyakarta, Jl. Ring Road Utara, \\ Condong Catur, Sleman, 55283, Indonesia \\ * Corresponding Author. E-mail : fajarsleman@gmail.com. Telp : 0856-2630-360
}

\begin{abstract}
Abstrak
Penelitian ini bertujuan untuk mengetahui hubungan tingkat harapan ideal dan persepsi aktual pengguna terhadap kualitas layanan yang diberikan website Pemerintah Desa Sidoluhur Godean, serta memberikan solusi dan implikasi manajerial yang dapat direncanakan untuk meningkatkan kualitas layanan website tersebut. Metode penelitian yang digunakan untuk melakukan evaluasi melalui pendekatan perhitungan integrasi modifikasi variabel webqual dalam kerangka Structural Equation Modelling (SEM) dan Importance Performance Analysis (IPA). Hasil dari penelitian ini, yaitu terdapat hubungan yang positif dan signifikan antara variabel kualitas layanan website, tingkat kepuasan, dan intensitas penggunaan yang membentuk model konseptual penelitian. Atribut yang sangat perlu untuk mendapat perhatian adalah masalah ketepatan waktu informasi, detail informasi, keamanan pengguna saat berinteraksi, ketepatan gambar, kesesuaian huruf dan kecepatan website.
\end{abstract}

Kata Kunci: Evaluasi Layanan Website, Dimensi Kualitas Website, Webqual Modifikasi, Important Performance Analysis.

\begin{abstract}
The aim of this study is to determine the relationship between the ideal level of expectations and the user's actual perceptions of the web quality services provided by the The Sidoluhur Godean Village, as well as providing solutions and managerial implications that can be planned to improve the quality of the website services. The method used to perform the evaluation through the integration of calculation webqual variables modifications approach within the framework of Structural Equation Modelling (SEM) and Importance Performance Analysis (IPA). This research, shows there is a positive and significant relationship among the variables of website service quality, satisfaction levels, and the intensity of system use. This relation forms the research conceptual model. The attributes that are necessary to get attention is the problem of updating information content, detailed information, user interaction security, image appropriation, font's suitability and speed time access to view website.
\end{abstract}

Keywords: Website Service Evaluation, Website Quality Dimension, Webqual Modification, Important Performance Analysis. 


\section{PENDAHULUAN}

Di era informasi seperti sekarang ini, internet telah menjadi sarana penting yang digunakan untuk mendistribusikan informasi dan layanan masyarakat (Luo, 2015).

Internet dan hal-hal lain yang berkaitan dengan World Wide Web telah mengubah paradigma organisasi umum dan khusus, dari yang dulunya menggunakan internet sebatas sebagai penyaji informasi menjadi suatu layanan yang bernilai bagi pembaca (Rababah dkk, 2016). Organisasi di atas dapat mengambil contoh kelembagaan pemerintahan yang dikenal dengan $E$ Government.

E-government sebagai bagian proses transformasi teknologi informasi, mempunyai berbagai manfaat antara lain biaya pengiriman layanan yang lebih efektif, layanan lebih terpadu, biaya administrasi lebih rendah, dan tampilan terpadu yang lebih memudahkan akses ke semua institusi pemerintah (Karunasena \& Deng, 2012).

Salah satu tahap awal dari pengembangan e-government di Indonesia adalah dengan pembuatan website di tiap-tiap kelembagaan pemerintah, termasuk unit pemerintahan terkecil yakni pemerintah desa. Portal atau website tersebut tentunya memerlukan evaluasi terhadap kegunaan informasi dan layanan (Santosa dkk, 2015).

Evaluasi website di atas dapat diukur dengan meneliti tingkat harapan dan persepsi pengguna. Arifin dkk, (2015) menjelaskan bahwa harapan dan persepsi pada akhirnya akan menentukan tingkat kepuasan konsumen terhadap suatu pelayanan. Setelah menikmati pelayanan yang diberikan, konsumen akan membandingkan antara harapan dan persepsi mereka tentang pelayanan tersebut.

Permasalahan yang muncul dari latar belakang di atas adalah hubungan tingkat harapan ideal dengan persepsi faktual pengguna terhadap kualitas layanan website. Lebih lanjut perlu dirumuskan tentang solusi dan implikasi manajerial yang dapat direncanakan untuk meningkatkan kualitas layanan website dalam memenuhi harapan penggunanya.

Hipotesis dalam penelitian ini adalah sebagai berikut. (1) H1: Kualitas informasi (information quality) mempunyai hubungan yang positif dengan kualitas layanan website. (2) H2: Kualitas layanan interaksi (service interaction quality) mempunyai hubungan yang positif dengan kualitas layanan website. (3) H3: Kualitas antarmuka pengguna (user interface quality) mempunyai hubungan yang positif dengan kualitas layanan website. (4) H4: Kualitas kegunaan (usability) mempunyai hubungan yang positif dengan kualitas layanan website.

Betchoo (2016) memiliki penilitian berjudul An Insight into the Practice of e-Government A road map for Contemporary Public Administration. Kelebihan penelitian ini adalah sinkronisasi antara tiga model e-Government yakni Government to Government Model (G2G), Government to Business (G2B) dan Government to Citizens (G2C). Kelemahan penelitian ini adalah tidak mencantumkan penelitian terdahulu sehingga penilaian terhadap jurnal ini menjadi kurang komprehensif. Penelitian yang tidak mencantumkan penelitian terdahulu 
akan sulit di analisis, karena penelitian terdahulu dapat digunakan sebagai bahan pembanding sehingga dapat diketahui pula progress evaluasi dari obyek penelitian.

Luo (2015) memiliki penelitian dengan judul Usability of E-government Portals in China. Kelebihan penelitian ini adalah karena menggunakan metode heuristic evaluation yang komprehensif. Kelemahan penelitian ini karena tidak melibatkan persepsi warga masyarakat. Hal ini memuncul justifikasi bahwa akan lebih utuh dan menyuluruh jika penelitian ini melibatkan persepsi pengguna.

Paz dan Pow-Sang (2016) dalam penelitiannya yang berjudul A Systematic Mapping Review of Usability Evaluation Methods for Software Development Process, menggunakan 215 hasil studi sebagai obyek penelitian. Penelitian ini telah membuktikan bahwa lima teknik menjadi yang paling sering digunakan. Lima teknik tersebut yakni teknik questionnaire, user testing, heuristic evaluation, interview, dan thinking aloud protocol.

\section{METODE}

Penelitian ini termasuk jenis penelitian deskriptif dengan pendekatan kuantitafif menggunakan survei.

Proses pengumpulan data yang dilakukan dalam penelitian ini adalah dengan melakukan survei dengan menyebarkan kuesioner kepada para responden (Santosa dkk, 2015).

Jenis pertanyaan yang digunakan dalam kuesioner adalah pertanyaan tertutup (closed ended question). Teknik pengambilan sampel yang dilakukan dalam penelitian ini adalah judgment sampling dengan sample warga Desa Sidoluhur Godean. Teknik ini diukur menggunakan enam point skala likert mulai dari 1 (sangat tidak setuju/penting) sampai 5 (sangat setuju/penting) untuk mengurangi resiko penyimpangan atau mengurangi resiko penyimpangan pengambilan keputusan pribadi dan mempunyai kehandalan yang tinggi (Chomeya, 2010).

Jumlah sampel dalam penelitian ini sebanyak 60 warga yang tersebar di tiga belas padukuhan yakni : Sokonilo, Berjo Kulon, Berjo Kidul, Berjo Wetan, Ngabangan, Jowah, Pandean, Kunden, Gatak, Dadapan, Serangan, Mertosutan, dan Tebon.

Data yang terkumpul akan dianalisis dengan teknik Importance Performance Analysis (IPA) untuk membandingkan penilaian warga terhadap pentingnya kualitas layanan (importance) dengan tingkat kualitas kinerja layanan (performance). Analisis ini merupakan teknik untuk melakukan identifikasi dari atribut-atribut (indikator) yang mempengaruhi kualitas layanan sebuah website. Hasil identifikasi dari atribut kualitas website ini berimplikasi pada atribut mana yang seharusnya ditingkatkan dan atribut mana yang seharusnya diperbaiki (Wicaksono \& Susanto, 2013). Data olahan ini kemudian dituangkan dalam grafik yang memiliki empat kuadran.

Berikut penjelasan untuk masing-masing kuadran di atas (Martilla dan James, 1977) :

1. Kuadran pertama: Tingkatkan kinerja (high importance dan low performance). Dianggap faktor yang sangat penting namun belum memuaskan untuk kondisi saat ini sehingga harus menjadi perhatian bagi manajemen untuk mengalokasikan sumber daya yang memadai. 
2. Kuadran kedua: Pertahankan kinerja (high importance dan high perfomance). Dianggap sebagai faktor penunjang bagi kepuasan konsumen sehingga manajemen wajib memastikan kinerja institusinya dapat mempertahankan prestasi yang telah dicapai.

3. Kuadran ketiga: Prioritas rendah (low importance dan low performance). Dianggap mempunyai tingkat kepuasan yang rendah sekaligus dianggap tidak terlalu penting oleh konsumen, sehingga manajemen tidak perlu memprioritaskan faktor tersebut.

4. Kuadran keempat: Cenderung berlebihan (low importance dan high performance). Dianggap tidak terlalu penting sehingga manajemen bisa mengalokasikan sumber daya yang terkait dengan faktor-faktor tersebut kepada faktor-faktor lain yang lebih membutuhkan peningkatan penanganan.

Pembagian kuadran yang terdapat pada IPA dapat dilihat pada Gambar 1 dibawah ini,

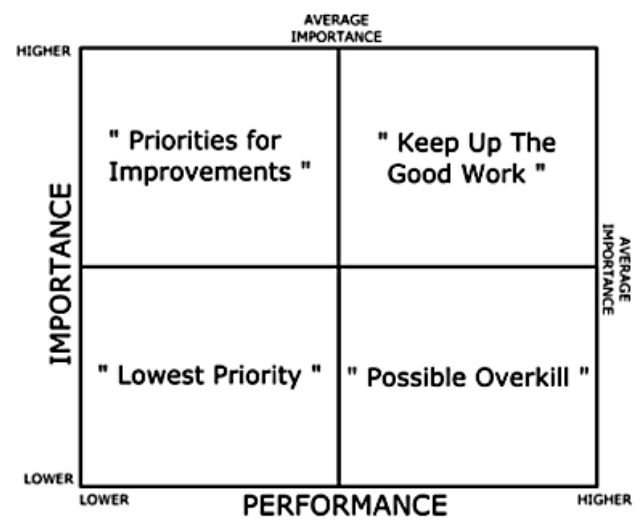

Gambar 1. Kuadran IPA (Brandt, 2000)

Pengolahan dan analisis data yang digunakan dalam penelitian ini menggunakan program/ software statistik SPSS dan Microsoft Excel. Gambar 2 berikut menunjukkan alur penelitian yang telah disusun. 


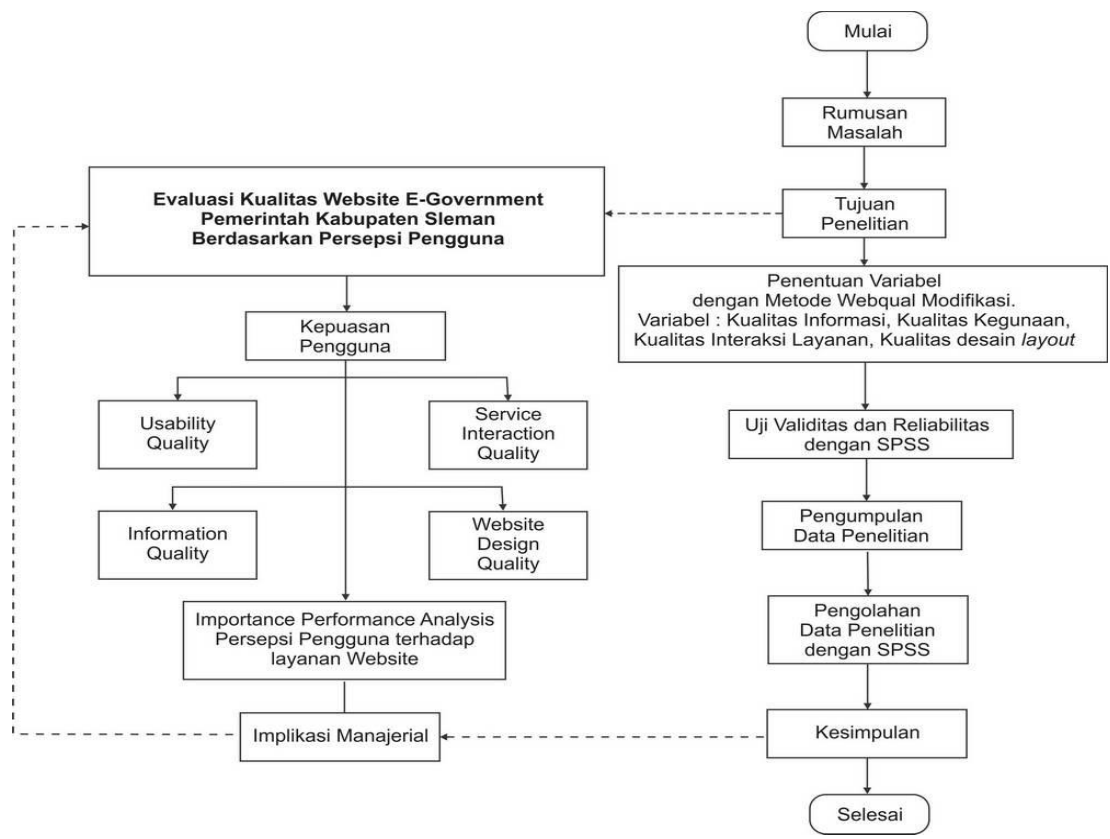

Gambar 2. Alur Penelitian

\section{HASIL DAN PEMBAHASAN}

Hipotesis dapat diketahui dengan pengujian pengaruh variabel independen terhadap variabel dependen. Pengaruh ini dapat dilihat dari nilai C.R. Variabel dikatakan ada pengaruh atau signifikan jika $\mathrm{P} \leq 0,05$. Berikut hasil ringkasan pengujian hipotesis peneitian:

Tabel 1. Hasil Pengujian Hipotesis

\begin{tabular}{|c|c|c|c|c|c|}
\hline & $\begin{array}{r}\text { Estimasi } \\
\text { Standard }\end{array}$ & Estimate & C.R. & $\mathrm{P}$ & Signifikansi \\
\hline X1.3 <--- Kualitas_Website & .773 & 1.757 & 4.903 & $* * *$ & Signifikan \\
\hline X1.2 <-- Kualitas_Website & .599 & 1.477 & 3.901 & $* * *$ & Signifikan \\
\hline X1.1 <--- Kualitas_Website & .611 & 1.000 & & & Signifikan \\
\hline X1.4 <-- Kualitas_Website & .981 & 1.764 & 4.628 & $* * *$ & Signifikan \\
\hline
\end{tabular}

Sumber: data diolah 2018

Penjelasan dari hasil uji hipotesis pengaruh antar masing-masing variabel di atas adalah sebagai berikut. (1) Indikator X1.1 (Kualitas informasi) mempengaruhi kualitas website sebesar 0,773. Hipotesis H1 terbukti : Kualitas informasi (information quality) mempunyai hubungan yang signifikan dan positif dengan kualitas layanan website. (2) Indikator X1.2 (Kualitas interaksi layanan) mempengaruhi kualitas website sebesar 0,599. Hipotesis $\mathrm{H} 2$ terbukti : Kualitas layanan interaksi (service interaction quality) mempunyai hubungan yang signifikan dan positif dengan kualitas layanan website. (3) Indikator X1.3 (Kualitas antarmuka pengguna) mempengaruhi kualitas website sebesar 0,611. Hipotesis H3 terbukti : Kualitas antarmuka pengguna (user interface quality) mempunyai hubungan yang signifikan dan positif dengan kualitas layanan website. (4) Indikator X1.4 (Kegunaan) mempengaruhi kualitas website sebesar 0,981. Hipotesis H4 terbukti : Kualitas kegunaan (usability) mempunyai hubungan yang signifikan dan positif dengan kualitas layanan website. 
Data di atas kemudian di analisis dengan Importance-Perfomance Analysis (IPA).

Tabel 2. Perbedaan rata-rata antara Importance-Perfomance

\begin{tabular}{|l|r|r|r|l|}
\hline \multicolumn{1}{|c|}{ Atribut } & Importance & Performance & Gap & Sig \\
\hline Kualitas Informasi 1 & 4.28 & 4.03 & 0.2533 & 0.002 \\
\hline Kualitas Informasi 2 & 4.23 & 3.98 & 0.2467 & 0.004 \\
\hline Kualitas Informasi 3 & 4.20 & 3.56 & 0.6400 & 0.000 \\
\hline Kualitas Informasi 4 & 4.15 & 3.85 & 0.3000 & 0.001 \\
\hline Kualitas Informasi 5 & 4.15 & 3.93 & 0.2167 & 0.009 \\
\hline Kualitas Informasi 6 & 4.17 & 3.52 & 0.6500 & 0.000 \\
\hline Kualitas Informasi 7 & 4.13 & 3.67 & 0.4667 & 0.000 \\
\hline Kualitas Interaksi Layanan 1 & 4.20 & 3.51 & 0.6900 & 0.000 \\
\hline Kualitas Interaksi Layanan 2 & 4.07 & 3.53 & 0.5333 & 0.000 \\
\hline Kualitas Interaksi Layanan 3 & 4.02 & 3.58 & 0.4333 & 0.000 \\
\hline Kualitas Interaksi Layanan 4 & 4.12 & 3.65 & 0.4667 & 0.000 \\
\hline Kualitas Interaksi Layanan 5 & 4.08 & 3.53 & 0.5500 & 0.000 \\
\hline Kualitas Interaksi Layanan 6 & 4.03 & 3.40 & 0.6333 & 0.000 \\
\hline Kualitas Desain Antar Muka 1 & 4.21 & 3.45 & 0.7600 & 0.012 \\
\hline Kualitas Desain Antar Muka 2 & 4.18 & 3.35 & 0.8333 & 0.007 \\
\hline Kualitas Desain Antar Muka 3 & 4.10 & 3.73 & 0.3667 & 0.000 \\
\hline Kualitas Desain Antar Muka 4 & 4.17 & 3.88 & 0.2833 & 0.008 \\
\hline Kualitas Desain Antar Muka 5 & 4.23 & 3.90 & 0.3333 & 0.009 \\
\hline Kualitas Desain Antar Muka 6 & 4.18 & 3.62 & 0.5667 & 0.000 \\
\hline Kualitas Desain Antar Muka 7 & 4.15 & 3.90 & 0.2500 & 0.007 \\
\hline Kualitas Desain Antar Muka 8 & 4.08 & 3.38 & 0.7000 & 0.000 \\
\hline Usability 1 & 4.25 & 3.93 & 0.3167 & 0.012 \\
\hline Usability 2 & 4.13 & 3.88 & 0.2500 & 0.013 \\
\hline Usability 3 & 4.12 & 3.68 & 0.4333 & 0.000 \\
\hline Usability 4 & 4.15 & 3.98 & 0.1667 & 0.039 \\
\hline Usability 5 & 4.08 & 3.82 & 0.2667 & 0.015 \\
\hline Usability 6 & 4.17 & 4.00 & 0.1667 & 0.038 \\
\hline Usability 7 & 4.25 & 3.87 & 0.3833 & 0.001 \\
\hline
\end{tabular}

Tabel 2 menyajikan perhitungan rata-rata, nilai gap dari tiap-tiap atribut kualitas layanan website. Berdasarkan nilai rata-rata (mean) masing-masing atribut kualias layanan website, selanjutnya dihitung selisih (gap) antara dimensi importance dan performance (importance dikurangi performance) serta nilai $t$ statistik dengan tingkat signifikansi 95\% (á=0,05). Dari tabel t-test terlihat bahwa terdapat signifikansi perbedaan nilai importance dan performance untuk seluruh atribut. Dari data tabel tersebut terlihat bahwa rata-rata keseluruhan dimensi importance (harapan) sebesar 4,15 dan rata-rata dimensi performance (persepsi) sebesar 3,72. 
Data dalam tabel 2 di atas, kemudian di masukkan dalam grafik berikut.

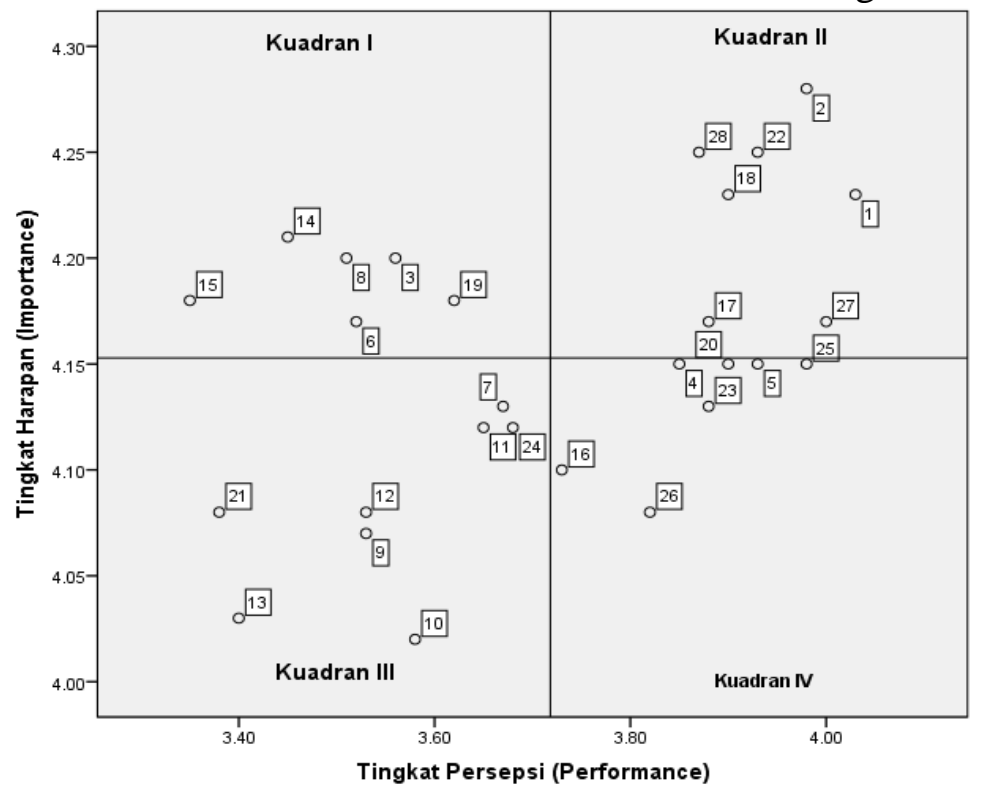

Gambar 3. Diagram Importance-Performance Analysis

Gambar 3 menunjukkan sebaran posisi relatif dari atribut kualitas layanan website dalam format matrik, dimana nilai importance sebagai garis (sumbu) vertikal dan nilai performance sebagai garis (sumbu) horisontal yang disajikan dalam bentuk diagram kartesius yang terbagi dalam empat kuadran.

Dari Gambar 3 dapat diketahui bahwa atribut kualitas informasi yang menempati kuadran satu antara lain: atribut nomor 3 dan 6. Kuadran kedua ditempati atribut nomor 1,2,4 dan 5. Kuadran ketiga hanya terdapat satu atribut yakni atribut nomor 7 .

Atribut kualitas interaksi layanan yang menempati kuadran satu hanya atribut nomor 8. Kuadran ketiga terdapat lima atribut yakni atribut nomor 9,10, 11, 12 dan 13 .

Terdapat dua atribut kualitas desain antar muka yang menempati kuadran satu yakni nomor 14 dan 15. Kuadran kedua ditempati atribut nomor 17 dan 18 . Kuadran ketiga terdapat satu atribut yakni atribut nomor 21. Pada kuadran keempat terdapat dua atribut yakni nomor 16 dan 20 .

Atribut kualitas kegunaan yang menempati kuadran dua antara lain: atribut nomor 22, 27 dan 28. Kuadran ketiga hanya ditempati atribut nomor 24. Kuadran keempat terdapat dua atribut yakni atribut nomor 23, 25 dan 26.

\section{Solusi dan Implikasi Manajerial}

Dari Gambar 3 dapat diketahui bahwa prioritas utama pengembangan website Pemerintah Desa Sidoluhur antara lain :

a. Website menyediakan informasi yang tepat waktu.

Persepsi warga tentang informasi desa yang kekinian masih rendah, padahal harapan mereka tinggi tentang hal ini. Hal ini terbukti dari publikasi berita yang kurang teratur bila dilihat dari tanggalnya. Padahal program atau kegiatan oleh 
Pemerintah Desa selalu ada setiap pekan. Solusi dan implikasi manajerial dari permasalahan ini antara lain :

1) Pembenahan pada sintaksis kode Hypertext Preproccessor (PHP) khususnya pada baris perintah urutan berita.

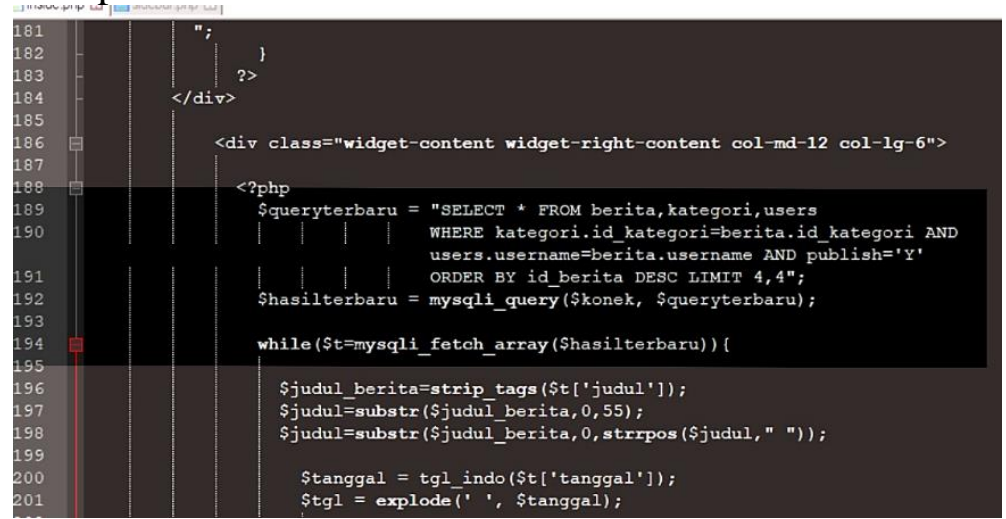

Gambar 4. Baris Kode Perintah Kolom Berita

Perintah "ORDER BY id_berita DESC" pada Gambar 4 di atas dapat diganti dengan "ORDER BY tanggal DESC".

2) Pembuatan Prosedur Standar Operasional (SOP) publikasi informasi,

b. Website menyediakan informasi yang detail.

Persepsi warga tentang informasi desa yang detail masih rendah, padahal harapan mereka tinggi tentang hal ini. Solusi dan implikasi manajerial dari permasalahan ini adalah dengan menerapkan teori apa, siapa, kapan, dimana, mengapa, dan bagaimana atau lebih dikenal dengan 5W1H (what, who, when, where, why dan how). Berita terkategori sebagai berita lengkap jika memiliki informasi 5W1H yang menjadi informasi inti berita (Ilyas dan Khodra, 2015).

c. Pengguna merasa aman ketika melakukan interaksi

Persepsi warga tentang keamanan website masih rendah, padahal harapan mereka tinggi tentang hal ini. Penyebab dan solusi dari kesenjangan tersebut kami jelaskan di bawah ini.

1) Website Desa Sidoluhur masih menggunakan protokol Hypertext Transfer Protocol (HTTP). Protokol HTTP bukanlah protokol yang aman (Singh dan Kumar, 2016).

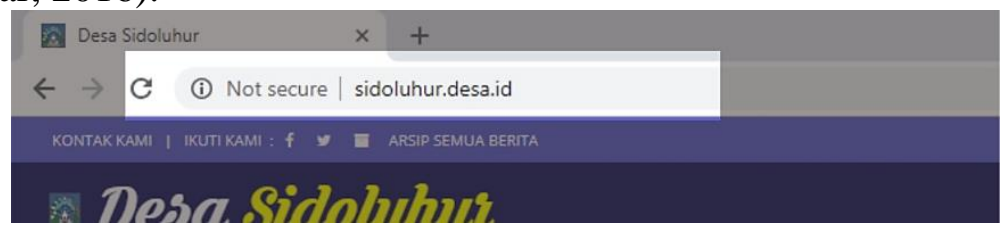

Gambar 4. Website Sidoluhur masih menggunakan HTTP

Solusi dari permasalahan di atas adalah dengan mengganti protokol HTTP menjadi Hypertext Transfer Protocol Secure (HTTPS).

2) Keamanan interaksi juga dibutuhkan saat pengunjung mengirimkan pesan lewat halaman saran, kritik dan aduan. 


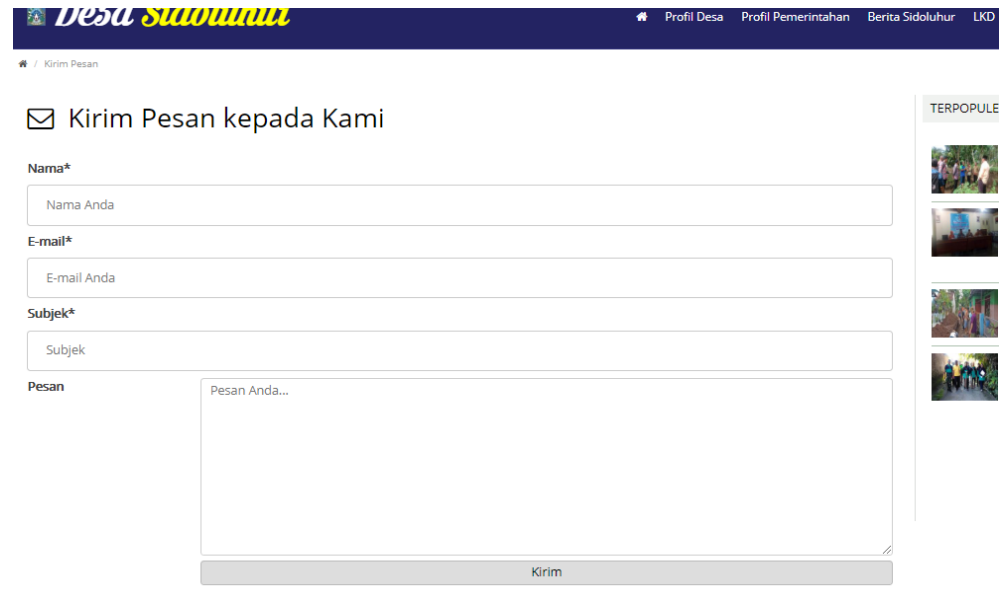

Gambar 5. Halaman Saran, Kritik dan Aduan

Pesan yang cukup sensitif harus disimpan oleh pengelola website dengan melindungi kerahasiaan data pengirim pesan. Informasi perlindungan data pengunjung ini sebaiknya dituliskan pada halaman saran, kritik dan aduan. Dengan demikian pengirim dapat lebih tenang saat mengirimkan pesan.

d. Website menggunakan gambar yang tepat

Persepsi warga tentang penggunaan gambar pada website masih rendah, padahal harapan mereka tinggi tentang hal ini. Penyebab dan solusi dari kesenjangan tersebut kami jelaskan di bawah ini.

1) Kebutuhan tentang poster kegiatan

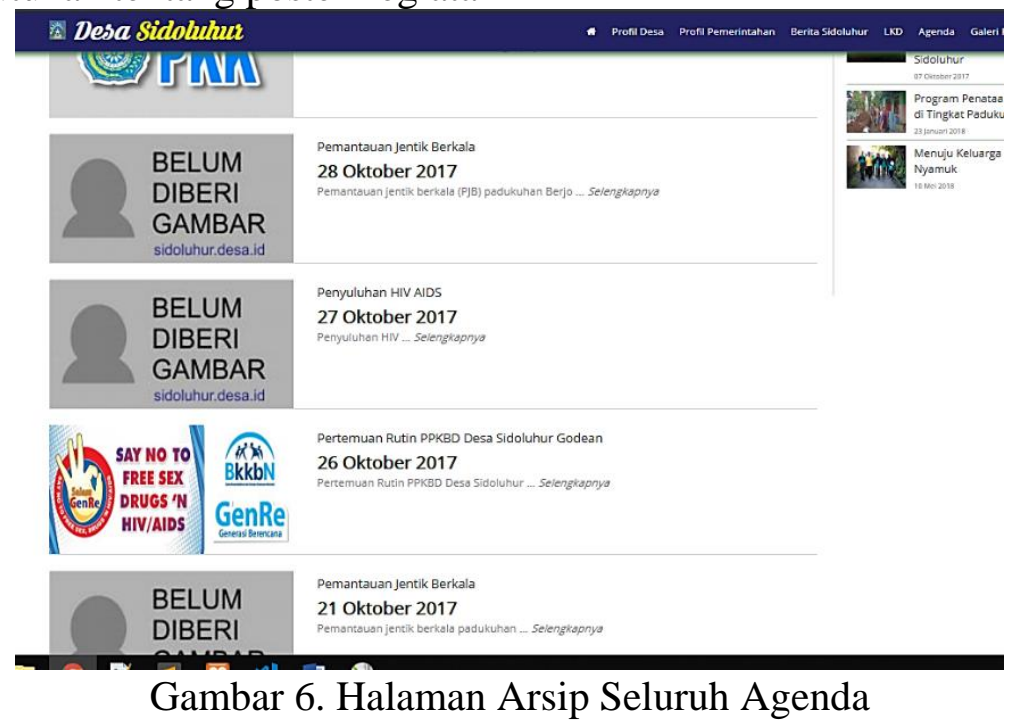

Pada Gambar 6 dapat diketahui bahwa publikasi kegiatan di halaman agenda belum tertata dengan baik. Gambar yang masih kosong, menunjukkan bahwa pengelola belum mempersiapkan poster ataupun gambar yang sesuai dengan kegiatan. Pengunjung website akan lebih tertarik konten agenda dengan gambar atau poster yang relevan. 
2) Kebutuhan galeri foto tentang pembangunan dan pemberdayaan masyarakat
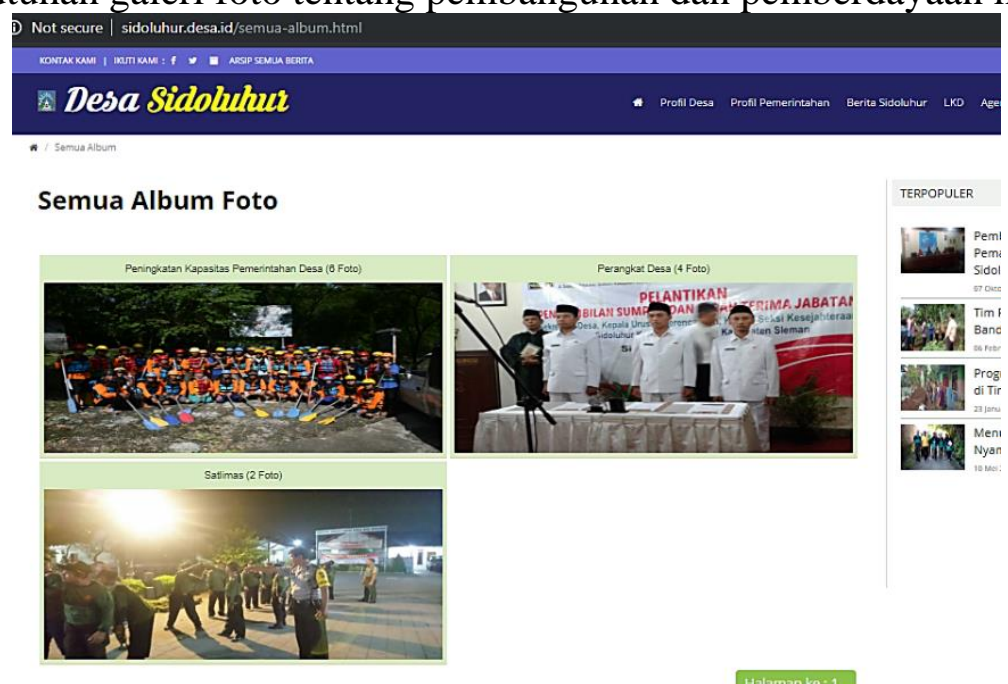

Gambar 7. Halaman Album Foto

Pada Gambar 7 di atas hanya terdapat tiga album foto yang kesemuanya adalah agenda bidang pemerintahan desa.

Dalam Peraturan Menteri Dalam Negeri Nomor 20 Tahun 2018, terdapat lima bidang yang menjadi rencana kerja pemerintah desa. Lima bidang tersebut antara lain : Bidang Penyelenggaraan Pemerintahan, Bidang Pembangunan, Bidang Pembinaan, Bidang Pemberdayaan dan Bidang Penanggulan Bencana.

Supaya terwujud keutuhan informasi, sebaiknya galeri foto di bidang selain penyelenggaran pemerintahan juga dicantumkan. Terlebih bidang pembangunan dan pemberdayaan masyarakat yang mendapatkan sorotoan luas dari pemangku kebijakan.

e. Website menggunakan font (huruf) yang sesuai.

Persepsi warga tentang penggunaan font yang sesuai pada halaman website masih rendah, padahal harapan mereka tinggi tentang hal ini. 


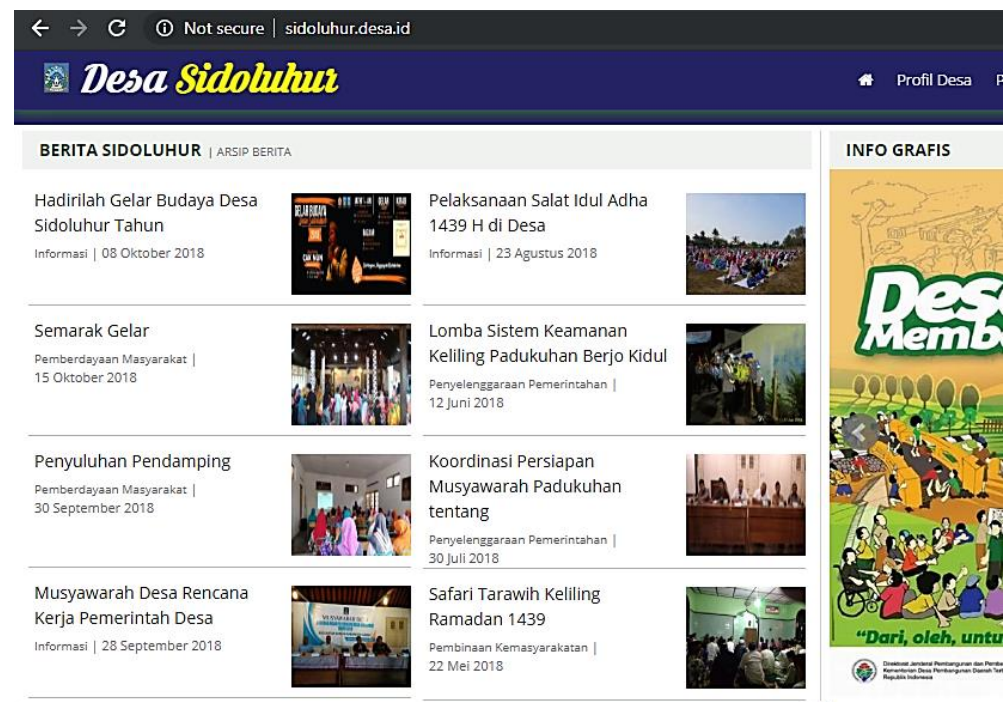

Gambar 8. Tampilan Kolom Berita

1) Pada Gambar 8 dapat diketahui bahwa judul berita masih menggunakan berat huruf (font-weight) dengan skala nilai 400. Skala ini menurut Sihombing (2015) tergolong dalam jenis Regular, Normal, Plain, Roman, Standard.

Walaupun dalam sebuah jenis huruf memiliki variasi berat, namun karakteristik fisik tetap memiliki kesamaan. Perbedaan berat dapat memberikan dampak visual yang berbeda, seperti huruf bold karena ketebalannya memiliki potensi yang kuat dalam menarik perhatian mata. Oleh karena itu, sebaiknya huruf judul berita menggunakan berat huruf bold dengan skala nilai 700 atau semi bold dengan nilai 600 .

2) Pada Gambar 8 dapat diketahui bahwa kategori dan tanggal berita yang tercantum di bawah judul berita belum rapi.

Hal ini terjadi karena penyebutan istilah kategori terlalu panjang. Solusi dari permasalahan ini adalah dengan simplifikasi istilah kategori yakni :

a) Penyelenggaraan Pemerintahan menjadi Pemerintahan

b) Pembinaan Kemasyarakatan menjadi Pembinaan

c) Pemberdayaan Masyarakat menjadi Pemberdayaan

Simplifikasi di atas tidak mengurangi substansi dari istilah kategori di masing-masing bidang.

Penyederhanaan istilah di atas juga akan berdampak pada kerapian huruf, yang awalnya dua baris bisa menjadi satu baris.

f. Kecepatan download pada halaman website

Persepsi warga tentang kecepatan download pada halaman website masih rendah, padahal harapan mereka tinggi tentang hal ini. Solusi dan implikasi manajerial dari permasalahan ini antara lain :

1) Dengan melakukan general test pada bagian-bagian penting dari website yang banyak disediakan situs websiteoptimization di internet seperti GTMetrix, sehingga diperoleh hasil analisis dan rekomendasi beberapa catatan apakah content dari website belum perlu dirombak atau harus melalukan perombakan 
content karena ada yang sudah over standart, sehingga memiliki dasar acuan untuk melakukan perombakan ini (Wicaksono \& Susanto, 2013).

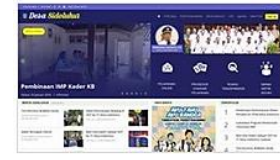

Latest Performance Report for:

http://sidoluhur.desa.id/

Report generated: Tue, Mar 20, 2018, 10:18 PM- 0700

Test Server Region: It I Vancouver, Canada

Using: Chrome (Desktop) 62.0.3202.94, PageSpeed 1.15-gt1
YSlow 31.8

(1).

Page Details
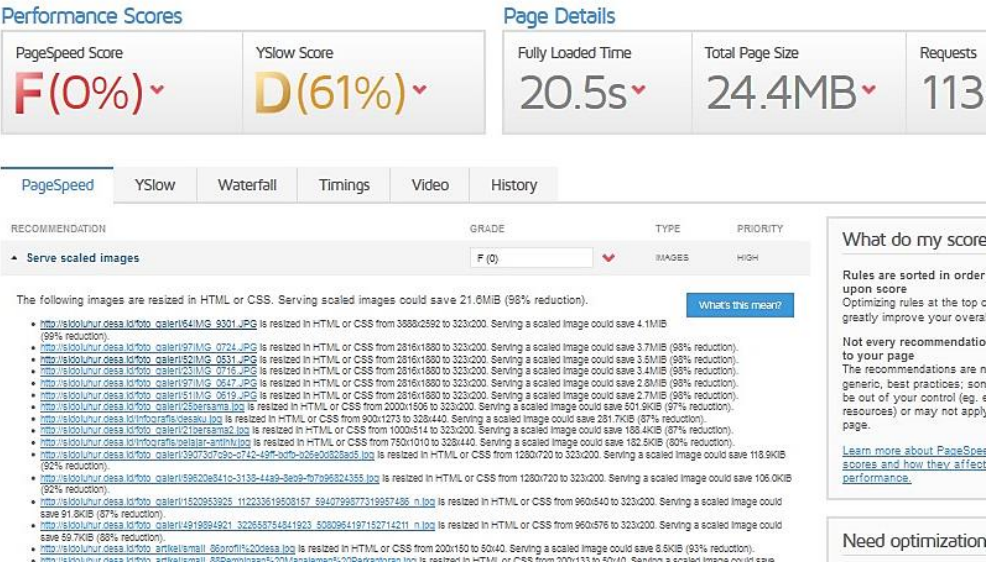

Gambar 9. Hasil analisis GT Metrix

Hasil analisis dari GT Metrix seperti pada Gambar 9 diantaranya adalah perlunya Serve Scaled Images pada foto peraga (thumbnails). Sebagai contoh adalah pada halaman beranda dan halaman galeri foto. Kedua halaman tersebut mencantumkan foto peraga yang diambil dari foto ukuran asli. Ukuran optimal kolom untuk foto peraga sendiri adalah 300 x 200, sedangkan foto asli dapat mencapai ukuran 3888 x 2592.

Solusi dari permasalahan ini adalah dengan modifikasi bahasa pemrograman website yang diterapkan, sehingga dapat otomatis mengubah ukuran foto asli menjadi foto peraga.

2) Mengambil fasilitas penambah kecepatan yang terdapat dalam penyedia hosting.

Memilih paket atau fasilitas hosting dari penyedia yang terpercaya merupakan bukti pembeda antara website berkecepatan tinggi dengan yang lamban (Shaw, 2018).

Penyedia layanan hosting website Desa Sidoluhur adalah Hostinger Indonesia yang beralamat di www.hostinger.co.id. Penyedia layanan hosting ini diketahui mempunyai salah satu paket yakni Cloudflare yang dapat meningkatkan performa website termasuk menambah kecepatan website. Oleh karena itu, sebaiknya pengelola website mengambil fasilitas ini.

\section{SIMPULAN}

Berdasarkan hasil evaluasi kualitas website dengan menggunakan modifikasi metode Webqual modifikasi dan analisis importance-performance, dapat diambil kesimpulan sebagai berikut. (1) Hasil penelitian menunjukkan bahwa tingkat kualitas website Pemerintah Desa Sidoluhur belum sesuai dengan harapan 
pengguna. Hal ini terbukti dari adanya perbedaan rata-rata antara harapan ideal dengan persepsi aktual pengguna pada masing-masing dimensi website. Nilai ratarata keseluruhan dimensi importance (harapan) sebesar 4,15 dan rata-rata dimensi performance (persepsi) sebesar 3,72. (2) Berdasarkan integrasi analisis Webqual dengan Importance Performance Analysis (IPA) yang diukur dari tiap-tiap atributnya menemukan bahwa atribut website Pemerintah Desa Sidoluhur yang menjadi prioritas evaluasi adalah masalah ketepatan waktu informasi, detail informasi, keamanan pengguna saat berinteraksi, ketepatan gambar, kesesuaian huruf dan kecepatan website.

\section{DAFTAR PUSTAKA}

Arifin, S.R.; Nugroho, E.; Hartono, B.S.; (2015). Analisis Kualitas Layanan Website Universitas Hasanuddin Dengan Metode Webqual 4.0 Modifikasi, Teknomatika Vol. 8, No. 1

Betchoo, N.K., (2016). An Insight into the Practice of e-Government A road map for Contemporary Public Administration, International Journal of Trend in Research and Development

Brandt, D.R., (2000). An “Outside-In” Approach to Determining Customer Driven Priorities for Improvement and Innovation, White Paper Series

Chomeya, R., (2010). Quality of Psychology Test Between Likert Scale 5 and 6 Points, Journal of Social Sciences

Ilyas, R. dan Khodra, M.L., (2015). Ekstraksi Informasi 5W1H pada Berita Online Bahasa Indonesia, Jurnal Cybermatika Vol. 3 No. 1, Juni 2015, School of Electrical Engineering and Informatics, Institut Teknologi Bandung.

Karunasena, K., dan Deng, H., (2012). Critical factors for evaluating the public value of e-government in Sri Lanka, Government Information Quarterly

Luo, Simin., (2015). Usability of E-government Portals in China (Case Study: www.hubei.gov.cn), Bachelor's Thesis in Business Information Technology, Lahti University of Applied Sciences, Degree Programme in Business Information Technology

Martilla, J.A. and James, J.C. (1977). Importance-Performance Analysis. Chicago: Journal of Marketing, 41, 77-79.

Paz, F., dan Pow-Sang, J.A., (2016). A Systematic Mapping Review of Usability Evaluation Methods for Software Development Process, International Journal of Software Engineering and Its Applications

Rahabah, O.M., Alshraideh, M., Abushariah, M.A.M., Manaseer, S., dan AlQisi, M., (2016). Optimizing the Process of Developing E-Government Website using Decision Support System, AcademicJournals Scientific Research and Essays

Santosa, B.S.; Anwar, M.F dan Hermawati, S., (2015). Analisis Kualitas Website Menggunakan Metode Webqual Dan Importance - Performance Analysis (IPA) Pada Situs Kaskus, Universitas Gunadarma, Kota Depok

Shaw, Alan., (2018). Site Speed Secrets: The Ultimate Guide To Speed Up Your Website \& Increase Conversions, https://toptenwebhostingsites.com

Wicaksono, B.Y., dan Susanto, A., (2013). Evaluasi Kualitas Layanan Website Pusdiklat BPK RI Menggunakan Metode Webqual Modifikasian dan 
Importance Performance Analysis, JNTETI 